\title{
Er:YAG Laser for Brackets Bonding: A SEM Study after Debonding
}

\author{
G. Ierardo, ${ }^{1}$ G. Di Carlo, ${ }^{1}$ F. Petrillo, ${ }^{1}$ V. Luzzi, ${ }^{1}$ I. Vozza, ${ }^{1}$ G. Migliau, ${ }^{1}$ \\ R. Kornblit, ${ }^{1}$ J. P. Rocca, ${ }^{2}$ and A. Polimeni ${ }^{1}$ \\ ${ }^{1}$ Department of Oral and Maxillofacial Science, "Sapienza" University of Rome, Via Caserta 6, 00161 Rome, Italy \\ ${ }^{2}$ Faculty of Odontology, University Hospital "St. Roch”, University of Nice-Sophia Antipolis, 5 rue Pierre Dévoluy, 06006 Nice, France \\ Correspondence should be addressed to G. Di Carlo; gdc_dds@yahoo.it
}

Received 4 August 2014; Revised 23 September 2014; Accepted 23 September 2014; Published 22 October 2014

Academic Editor: Romeo Umberto

Copyright (C) 2014 G. Ierardo et al. This is an open access article distributed under the Creative Commons Attribution License, which permits unrestricted use, distribution, and reproduction in any medium, provided the original work is properly cited.

\begin{abstract}
Background. The introduction of Er:YAG laser in dentistry for ablation of hard tissues advocated an alternative method of enamel etching for orthodontics purpose. Materials and Methods. 55 extracted human third molars were inserted in acrylic resin blocks and divided into five groups of 11 teeth. Group 1 was treated with $37 \%$ orthophosphoric acid for 30 seconds. Group 2 was treated with laser irradiation (Er:YAG Fidelius III, Fotona, Slovenia) at $80 \mathrm{~mJ}$ and $4 \mathrm{~Hz}$. Group 3 underwent laser treatment $(80 \mathrm{~mJ}, 4 \mathrm{~Hz})$, followed by $37 \%$ orthophosphoric acid for 30 seconds. The teeth in Group 4 were treated with laser at $40 \mathrm{~mJ}$ and $10 \mathrm{~Hz}$. The teeth in Group 5 were treated with laser $(40 \mathrm{~mJ}, 10 \mathrm{~Hz})$, followed by $37 \%$ orthophosphoric acid for 30 seconds. The adhesive remnant index was determined after debonding. Results. Kruskas-Wallis test showed that location parameters (median and mean) are significantly different between Groups 2 and 4 when compared with control group; on the contrary no significant difference was detected between Groups 3 and 5 with the controls. Conclusion. The use of Er:YAG laser alone, as in Groups 2 and 4, showed no significant advantages over phosphoric acid in the bonding procedure for orthodontics brackets.
\end{abstract}

\section{Introduction}

Phosphoric acid etching is the gold standard method of enamel preparation before application of bonding resins for orthodontic brackets [1]. Enamel etching changes the tooth surface from being of low-energy and hydrophobic to being of high-energy and hydrophilic, increasing the surface area for bonding [2]. Studies have demonstrated that this kind of attachment can have disadvantages, such as enamel decalcification, which leaves the enamel surface susceptible to acid attack (cavity formation) under orthodontic brackets [3-6]. One of the most important challenges in orthodontic treatment, however, is the frequent debonding of brackets, with the consequent lengthening of treatment duration.

With the recent introduction of erbium-doped yttrium aluminum garnet (Er:YAG) laser in dentistry for the ablation of hard tissues, including enamel and dentin, laser enamel preparation has been proposed as an alternative to phosphoric acid etching [7-9]. The Er:YAG laser can effectively modify enamel and dentin surfaces because of its $2.94 \mathrm{~mm}$ wavelength emission, which coincides with the main absorption band of water and $\mathrm{OH}$ - groups in hydroxyapatite [10].

In dentistry, the Er:YAG laser is primarily used to ablate hard tissues (enamel, dentin, and bone), but also to treat soft tissues [11-14]. Many papers [15-17] have reported that Er:YAG laser ablation of enamel and dentin is effective and efficient without causing heat damage to the pulp and without carbonization or cracks in the irradiated enamel and dentin. Moreover, use of the Er:YAG laser for dental hard tissue treatment, such as caries removal, cavity preparation, and enamel etching within certain parameters, is both safe and effective [18-21]. Additionally, the surface created by laser etching is reportedly resistant to carious attacks [22]. One study reported that the ultrastructural morphological 
changes in the surface enamel of permanent teeth after irradiation with Er:YAG laser were similar to lava flow, with an opened prism core and modification of the prism form [23]. To evaluate the advantages of the Er:YAG laser for enamel surface preparation before orthodontic bracket bonding, this study compared the adhesive remnant index (ARI) scores of teeth treated with different bonding procedures.

\section{Materials and Methods}

Our study included 55 intact human third mandibular and maxillary molars, extracted for orthodontic reasons. The inclusion criteria were noncarious lesions or enamel defects. The teeth were stored in saline solution at $4^{\circ} \mathrm{C}$ for no more than 28 days before insertion into acrylic resin blocks. The teeth were then divided in five groups of 11 teeth each. The first group (control group) was treated with $37 \%$ orthophosphoric acid (etching solution, ORMCO, USA) for 30 seconds. The second group was treated with laser irradiation (Er:YAG Fidelius III, Fotona, Slovenia) at $80 \mathrm{~mJ}$ and $4 \mathrm{~Hz}$. The third group underwent laser treatment $(80 \mathrm{~mJ}$ and $4 \mathrm{~Hz})$, followed by $37 \%$ orthophosphoric acid for 30 seconds. The teeth in the fourth group were treated with laser at $40 \mathrm{~mJ}$ and $10 \mathrm{~Hz}$. The fifth group underwent laser treatment $(40 \mathrm{~mJ}$ and $10 \mathrm{~Hz})$, followed by $37 \%$ orthophosphoric acid for 30 seconds.

To limit the area of enamel treated, a ceramic window was prepared with the exact dimensions of an orthodontic bracket. The ceramic window was held on the tooth surface by one operator while a second one applied the acid or laser light treatment only to the area within the window (Figure 1). The Er:YAG laser was used with the following parameters: VSP mode (pulse length, $100 \mu \mathrm{s}$ ) with the noncontact handpiece (mirror) in a focus mode (theoretical distance from the tooth surface, $10 \mathrm{~mm}$ ) using water/air spray in a continuous movement on a theoretical spot $0.8 \mathrm{~mm}$ in diameter (one spot next to another). The same operator (R. Kornblit) performed all laser enamel conditioning under $2.5 \times 350$ magnification (Univet medical eyewear). Immediately after enamel surface preparation, a bracket (Damon MX3-UR3, ORMCO) was attached by an experienced orthodontist (G. Ierardo) to each tooth following the different procedure for each single group as explained above. All teeth were dried before bonding placement. The bonding was performed using the same bonding adhesive (ORTHOSOLO, ORMCO) and a composite material (GRENGLOO, ORMCO) (Figures 2, 3, and 4). A microbrush was used to apply adhesive for 10 seconds on each surface, followed immediately by a thin layer of composite resin and a bracket. Teeth were cured for 30 seconds with a Coolbeam Orthodontic Curing Light (ORMCO). The bonded teeth were then kept in saline solution in five different plastic boxes at room temperature for 48 hours to allow complete polymerization. After 48 hours, all brackets were manually removed from the 55 teeth by the same experienced orthodontist (G. Ierardo), using a debonding plier (AEZ 8664008, ORMCO) designed for this procedure and exerting continuous rotational force toward the cervical part of the tooth (Figure 5). All 55 teeth were then sectioned in vertical (mesiodistal) and horizontal (cervical)

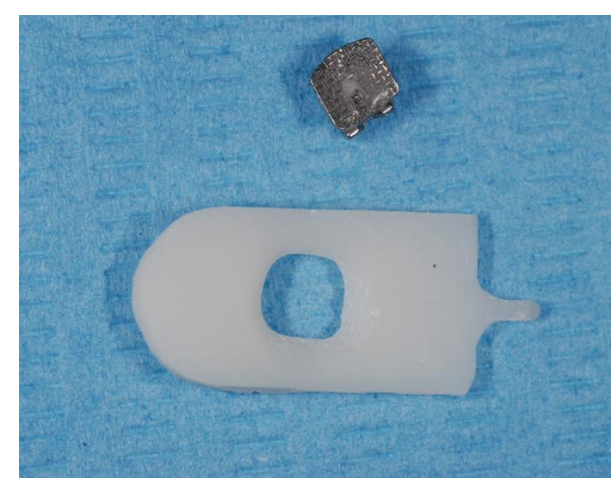

FIGURE 1: Ceramic mask equipped with the central hole of the size corresponding to the bracket base.

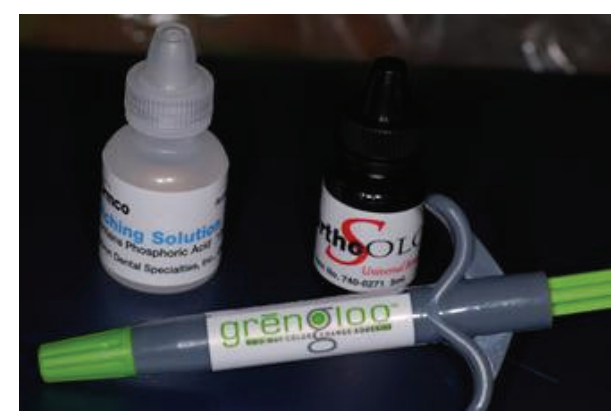

Figure 2: Phosphoric acid, bonding and composite resin.

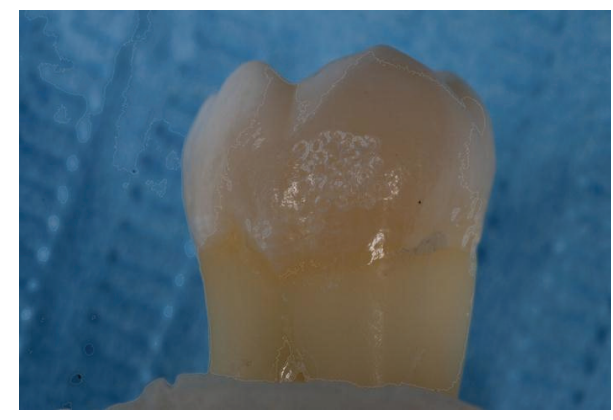

FIGURE 3: Enamel surface after conditioning with Er:YAG laser.

directions with an abrasive disc (COD: Yellow-Flex 220) by the same operator who performed the laser preparation ( $\mathrm{R}$. Kornblit).

All 55 samples were dipped for 30 seconds in an ultrasonic bath at $30^{\circ} \mathrm{C}$ to remove any residual powder left after sectioning. The samples were then kept in an oven at $40^{\circ} \mathrm{C}$ for 24 hours to remove all moisture, which can interfere with the vacuum needed for metallization. All samples were then conventionally metallized (Gold sputtering JEOL JFC 1100E) and observed under scanning electron microscope (SEM) (JEOL, JSM 5310 LV).

The ARI score was recorded by a senior student who was not informed regarding the different procedure applied for each tooth using a stereoscope (Nikon, Tokyo, Japan) at 10x magnification to determine the amount of residual adhesive 


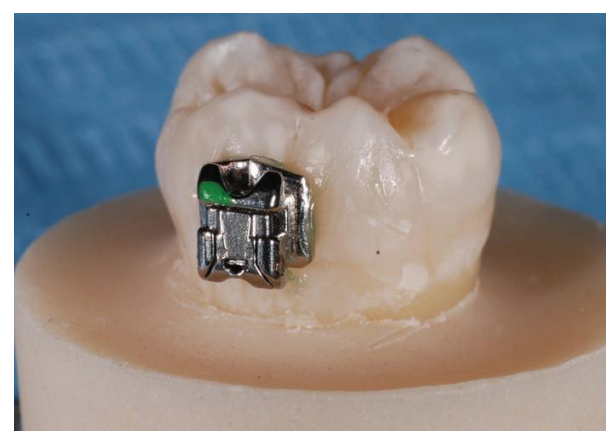

FIGURE 4: Bracket bonded on the enamel.

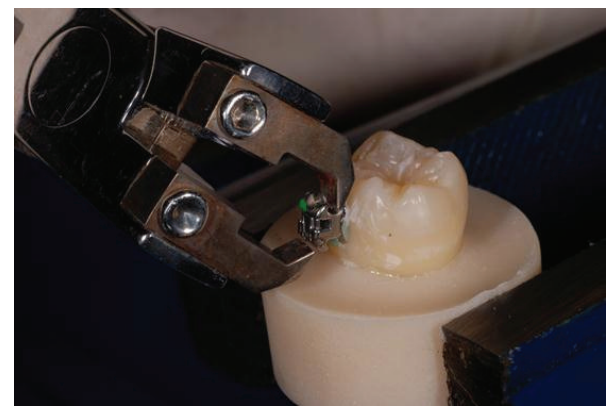

FIGURE 5: The sample stabilized by a vice, during the debonding.

remaining on each tooth, as described by Contreras-Bulnes et al. [24]. ARI scores were recorded using the 5-point scale described by Bishara and Trulove $[25,26]: 1=$ no composite adhering to the bracket base, $2=$ adhered composite on less than $10 \%$ of the bracket, $3=$ adhered composite on more than $10 \%$ but less than $90 \%$ of the bracket, $4=$ adhered composite on more than $90 \%$ of the bracket, and $5=$ composite adhering to the entire bracket base.

2.1. Statistical Analysis. The statistical analysis aims at testing whether location parameters for variable "ARI score" are statistically different between each treatment and the control group.

ARI score is an ordered categorical variable, so nonparametric statistics are used. Thus, median, interquartile difference, and Kruskal-Wallis rank sum test [27, 28] are used in place of mean, standard error, and ANOVA, which are suitable for numeric and normally distributed variables.

At first a graphical analysis is performed, drawing boxplots of "ARI score" in control group and in each treatment.

Secondly a single group analysis is performed, computing descriptive statistics (median, 1st and 3rd quartile) in each group (Table 1).

Thirdly the null hypothesis that the medians are the same in each group is tested against the alternative that they differ in at least one group by the Kruskal-Wallis rank sum test. As the null hypothesis is rejected, the after Kruskal-Wallis multiple comparison test between treatments versus control is performed.
TABLE 1: ARI score in whole sample and within groups-descriptive statistics.

\begin{tabular}{lcccccc}
\hline Group & n. obs. & Min. & 1st Q. & Median & 3rd Q. & Max. \\
\hline Control group & 11 & 1 & 1 & 1 & 1,5 & 2 \\
Group 2 & 11 & 2 & 2 & 4 & 4 & 4 \\
Group 3 & 11 & 1 & 2 & 2 & 3 & 4 \\
Group 4 & 11 & 1 & 1 & 3 & 3,5 & 5 \\
Group 5 & 11 & 1 & 1 & 3 & 3 & 5 \\
Whole sample & 55 & 1 & 1 & 2 & 3 & 5 \\
\hline
\end{tabular}

\section{Results}

The macroscopic observation of the composition material on the tooth surface was as follows.

(i) Group 1: 6 samples presented all the composite that remained on the tooth; in 5 samples part of the composite remained on the tooth and a part on the bracket.

(ii) Group 2: 4 samples presented all the composite that remained on the tooth; in 7 samples part of the composite remained on the tooth and a part on the bracket.

(iii) Group 3: 2 samples presented all the composite that remained on the tooth; in 8 samples part of the composite remained on the tooth and a part on the bracket and 1 sample presented all the composite that remained on the brackets.

(iv) Group 4: 4 samples presented all the composite that remained on the tooth; in 2 samples part of the composite remained on the tooth and a part on the bracket and 5 samples presented all the composite that remained on the brackets.

(v) Group 5: 5 samples presented all the composite that remained on the tooth; in 5 samples part of the composite remained on the tooth and a part on the bracket and 1 sample presented all the composite that remained on the brackets.

The descriptive statistics regarding ARI score for each single group is presented in Table 1 . No cracks were observed under SEM in any of the 55 samples. Boxplots highlight that all treatments show higher location and dispersion towards control group (Figure 6), so significant differences are expected. The null that location parameters of "ARI scores" are the same in each group is rejected, as the KruskalWallis rank sum test is 13.8863 and its $P$ value is 0.007667 . The Kruskal-Wallis multiple comparison test show that the null is rejected at 5\% significance level when comparing Group 2 and Group 4 to control and at 1\% significance level when comparing Group 2 and control (Table 2).

\section{Discussion}

ARI score results showed that the best composite resin retention to the enamel surface occurred in the control group 
TABLE 2: Results of Kruskal-Wallis multiple comparison test, treatment groups versus control (two-tailed).

\begin{tabular}{lccccccc}
\hline \multirow{2}{*}{ Comparisons } & \multirow{2}{*}{ Observed diff. } & \multicolumn{2}{c}{$10 \%$} & \multicolumn{3}{c}{ P value } \\
& & Critical diff. & Difference & Critical diff. & Difference & Critical diff. & Difference \\
\hline Control group-Group 2 & 23,636 & 15,312 & TRUE & 17,063 & TRUE & 20,653 & TRUE \\
Control group-Group 3 & 14,909 & 15,312 & FALLS & 17,063 & FALLS & 20,653 & FALLS \\
Control group-Group 4 & 17,273 & 15,312 & TRUE & 17,063 & TRUE & 20,653 & FALLS \\
Control group-Group 5 & 12,364 & 15,312 & FALLS & 17,063 & FALLS & 20,653 & FALLS \\
\hline
\end{tabular}

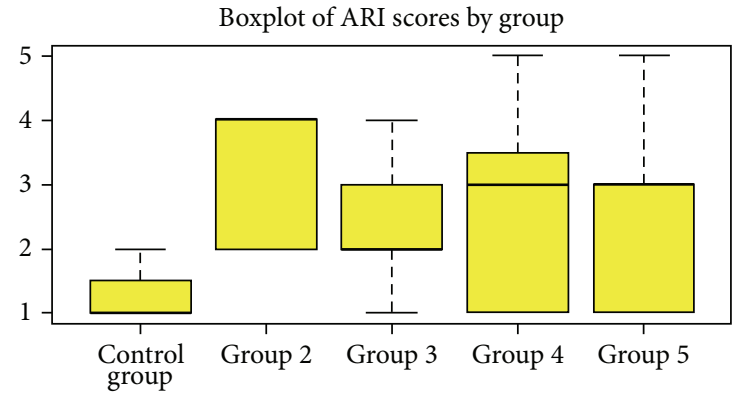

Figure 6

(Group 1), in which the enamel surfaces were prepared with acid etching alone. Groups 3 and 5, in which the enamel surfaces were treated with laser before acid etching, had better retention of the composite material to the tooth surface compared with Groups 2 and 4 . This finding can be explained by the fact that laser irradiation destroys enamel prisms in an indifferent way: the core of the prism as well as the walls is destroyed (Class 3 in the Silverstone classification), resulting in the typical lava flow appearance of the enamel surface under SEM $[20,21]$. This surface is poorly wettable by the bonding material; when phosphoric acid is applied to this surface, the acid attacks and regularizes the enamel's surface, increasing the microinfiltration capacity of the bonding material.

No cracks were observed at the periphery of the bracket attachment in any of the 55 samples, confirming that debonding forces did not damage the enamel surface. This lack of damage probably resulted from the use of an appropriate adhesive system and a specific instrument designed for bracket debonding. Moreover, for samples in which part of the composite remained on the tooth surface and part on the bracket, the group treated with laser alone did not have as homogeneous an adhesive area after debonding as that of the samples treated with acid. This finding confirmed the Silverstone Class 3 classification of enamel surfaces treated with Er:YAG laser.

Bishara and Trulove believed that bond failure at the enamel-adhesive interface was preferable to failure at other locations, because it leaves less residual adhesive and consequently requires less chair time for removal [25]. Several years later, the same author demonstrated that bond failure at the bracket-adhesive surface was better than at the enameladhesive interface, because it reduced the risk of enamel fracture and crazing during debonding [26]. We found that acid etching produced the most instances of debonding at the bracket-adhesive surface. We believe that reducing the risk of damage to the pulp is crucial when the debonding procedure is applied in orthodontics.

Authors have reported that laser etching is a valuable method comparable to the classical acid etching procedure [29-32]. These studies were based on shear bond strength measurements; the different laser irradiation protocol makes comparisons with the present study difficult. Moreover, as stated by Contreras-Bulnes et al., this method can result in substantial enamel loss [24]. Our results support those of Martínez-Insua et al., who reported that adhesion to dental hard tissues after Er:YAG laser etching is inferior to that obtained after conventional acid etching [33].

\section{Conclusion}

The use of Er:YAG laser alone showed no significant advantages over phosphoric acid etching in the bonding procedure for orthodontic brackets. Taking into account the cost and the additional time required to use the laser, this technology does not currently represent an added value for orthodontists in improving resin adhesion.

\section{Conflict of Interests}

The authors declare that there is no conflict of interests regarding the publication of this paper.

\section{References}

[1] F. C. Driessens, "Chemical adhesion in dentistry," International Dental Journal, vol. 27, no. 4, pp. 317-323, 1977.

[2] I. R. Reynolds, "A review of direct orthodontic bonding," British Journal of Orthodontics, vol. 2, pp. 171-180, 1975.

[3] D. H. Pashley, "The effects of acid etching on the pulpodentin complex," Operative Dentistry, vol. 17, no. 6, pp. 229-242, 1992.

[4] T. Oho and T. Morioka, "A possible mechanism of acquired acid resistance of human dental enamel by laser irradiation," Caries Research, vol. 24, no. 2, pp. 86-92, 1990.

[5] D. Ying, G. K. Chuah, and C.-Y. S. Hsu, "Effect of Er:YAG laser and organic matrix on porosity changes in human enamel," Journal of Dentistry, vol. 32, no. 1, pp. 41-46, 2004.

[6] H. Tokonabe, R. Kouji, H. Watanabe, Y. Nakamura, and K. Matsumoto, "Morphological changes of human teeth with Er:YAG laser irradiation," Journal of Clinical Laser Medicine \& Surgery, vol. 17, no. 1, pp. 7-12, 1999. 
[7] T. Özer, G. Başaran, and N. Berk, "Laser etching of enamel for orthodontic bonding," American Journal of Orthodontics and Dentofacial Orthopedics, vol. 134, no. 2, pp. 193-197, 2008.

[8] S. Üşümez, M. Orhan, and A. Üşümez, "Laser etching of enamel for direct bonding with an Er,Cr:YSGG hydrokinetic laser system," American Journal of Orthodontics and Dentofacial Orthopedics, vol. 122, no. 6, pp. 649-656, 2002.

[9] G. Basaran, T. Ozer, N. Berk, and O. Hamamci, "Etching enamel for orthodontics with an erbium, chromium:yttriumscandium- gallium-garnet laser system," Angle Orthodontist, vol. 77, no. 1, pp. 117-123, 2007.

[10] E. Firat, S. Gurgan, and N. Gutknecht, "Microtensile bond strength of an etch-and-rinse adhesive to enamel and dentin after Er:YAG laser pretreatment with different pulse durations," Lasers in Medical Science, vol. 27, no. 1, pp. 15-21, 2012.

[11] U. Keller and R. Hibst, "Experimental studies of the application of the Er:YAG laser on dental hard substances: II. Light microscopic and SEM investigations," Lasers in Surgery and Medicine, vol. 9, no. 4, pp. 345-351, 1989.

[12] A. Stabholz, R. Zeltser, M. Sela, B. Peretz, J. Moshonov, and D. Ziskind, "The use of lasers in dentistry: principles of operation and clinical applications," Compendium of Continuing Education in Dentistry, vol. 24, no. 12, pp. 935-949, 2003.

[13] C. M. Cobb, "Lasers in periodontics: a review of the literature," Journal of Periodontology, vol. 77, no. 4, pp. 545-564, 2006.

[14] M. D. Genovese and G. Olivi, "Use of laser technology in orthodontics: hard and soft tissue laser treatments," European Journal of Paediatric Dentistry, vol. 11, no. 1, pp. 44-48, 2010.

[15] C. Cozean, C. J. Arcoria, J. Pelagalli, and G. L. Powell, "Dentistry for the 21st century? Erbium:YAG laser for teeth," The Journal of the American Dental Association, vol. 128, no. 8, pp. 1080-1087, 1997.

[16] L. H. Sasaki, P. D. C. Lobo, Y. Moriyama et al., "Tensile bond strength and SEM analysis of enamel etched with Er:YAG laser and phosphoric acid: a comparative study in vitro," Brazilian Dental Journal, vol. 19, no. 1, pp. 57-61, 2008.

[17] V. Colucci, F. L. B. do Amaral, J. D. Pécora, R. G. PalmaDibb, and S. A. Milori Corona, "Water flow on erbium:yttriumaluminum-garnet laser irradiation: effects on dental tissues," Lasers in Medical Science, vol. 24, no. 5, pp. 811-818, 2009.

[18] R. Kornblit, D. Trapani, M. Bossù, M. Muller-Bolla, J. P. Rocca, and A. Polimeni, "The use of Erbium:YAG laser for caries removal in paediatric patients following minimally invasive dentistry concepts," European Journal of Paediatric Dentistry, vol. 9, no. 2, pp. 81-87, 2008.

[19] B. N. Cavalcanti, J. L. Lage-Marques, and S. M. Rode, "Pulpal temperature increases with Er:YAG laser and high-speed handpieces," Journal of Prosthetic Dentistry, vol. 90, no. 5, pp. 447451, 2003.

[20] V. R. Geraldo-Martins, F. R. P. Robles, and A. B. Matos, "Chlorhexidine's effect on sealing ability of composite restorations following Er:YAG laser cavity preparation," Journal of Contemporary Dental Practice, vol. 8, no. 5, pp. 26-33, 2007.

[21] A. L. L. Klein, L. K. A. Rodrigues, C. P. Eduardo, M. N. dos Santos, and J. A. Cury, "Caries inhibition around composite restorations by pulsed carbon dioxide laser application," European Journal of Oral Sciences, vol. 113, no. 3, pp. 239-244, 2005.

[22] J. A. Hoke, E. J. Burkes Jr., E. D. Gomes, and M. L. Wolbarsht, "Erbium:YAG (2.94 mum) laser effects on dental tissues," Journal of Laser Applications, vol. 2, no. 3-4, pp. 61-65, 1990.
[23] E. B. Groth, C. E. Mercer, and P. Anderson, "Microtomographic analysis of subsurface enamel and dentine following Er:YAG laser and acid etching," The European Journal of Prosthodontics and Restorative Dentistry, vol. 9, no. 2, pp. 73-79, 2001.

[24] R. Contreras-Bulnes, R. J. Scougall-Vilchis, L. E. RodríguezVilchis, C. Centeno-Pedraza, O. F. Olea-Mejía, and M. D. C. Z. Alcántara-Galena, "Evaluation of self-etching adhesive and Er:YAG laser conditioning on the shear bond strength of orthodontic brackets," The Scientific World Journal, vol. 2013, Article ID 719182, 5 pages, 2013.

[25] S. E. Bishara and T. S. Trulove, "Comparisons of different debonding techniques for ceramic brackets: an in vitro study. Part I. Background and methods," The American Journal of Orthodontics and Dentofacial Orthopedics, vol. 98, no. 2, pp. 145-153, 1990.

[26] S. E. Bishara and T. S. Trulove, "Comparisons of different debonding techniques for ceramic brackets: an in vitro study: part II. Findings and clinical implications," American Journal of Orthodontics and Dentofacial Orthopedics, vol. 98, no. 3, pp. 263-273, 1990.

[27] M. Hollander and D. A. Wolfe, Nonparametric Statistical Methods, John Wiley \& Sons, New York, NY, USA, 1973.

[28] S. Siegel and N. J. Castellan, Nonparametric Statistics for the Behavioral Sciences, McGraw-Hill, New York, NY, USA, 1988.

[29] G. Basaran, N. Hamamci, and A. Akkurt, "Shear bond strength of bonding to enamel with different laser irradiation distances," Lasers in Medical Science, vol. 26, no. 2, pp. 149-156, 2011.

[30] A. Gokcelik, Y. Ozel, E. Ozel et al., "The influence of Er:YAG laser conditioning versus self-etching adhesives with acid etching on the shear bond strength of orthodontic brackets," Photomedicine and Laser Surgery, vol. 25, no. 6, pp. 508-512, 2007.

[31] J.-H. Kim, O.-W. Kwon, H.-I. Kim, and Y. H. Kwon, "Effectiveness of an Er:YAG laser in etching the enamel surface for orthodontic bracket retention," Dental Materials Journal, vol. 24, no. 4, pp. 596-602, 2005.

[32] B.-S. Lee, T.-T. Hsieh, Y.-L. Lee et al., "Bond strengths of orthodontic bracket after acid-etched, Er:YAG laser-irradiated and combined treatment on enamel surface," Angle Orthodontist, vol. 73, no. 5, pp. 565-570, 2003.

[33] A. Martínez-Insua, L. D. S. Dominguez, F. G. Rivera, and U. A. Santana-Penín, "Differences in bonding to acid-etched or Er:YAG-laser-treated enamel and dentin surfaces," Journal of Prosthetic Dentistry, vol. 84, no. 3, pp. 280-288, 2000. 


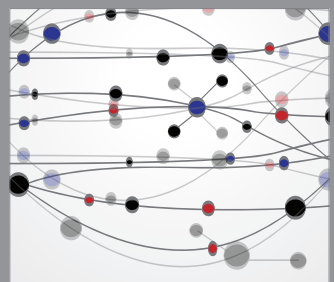

The Scientific World Journal
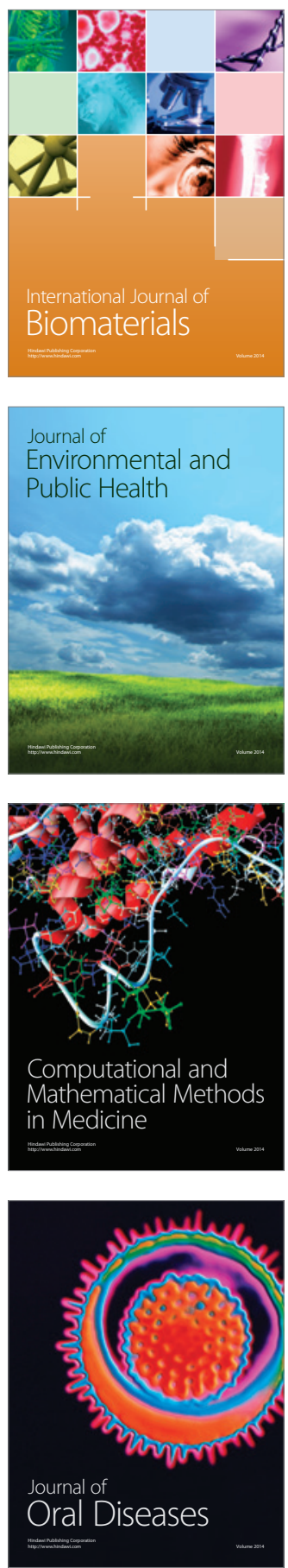
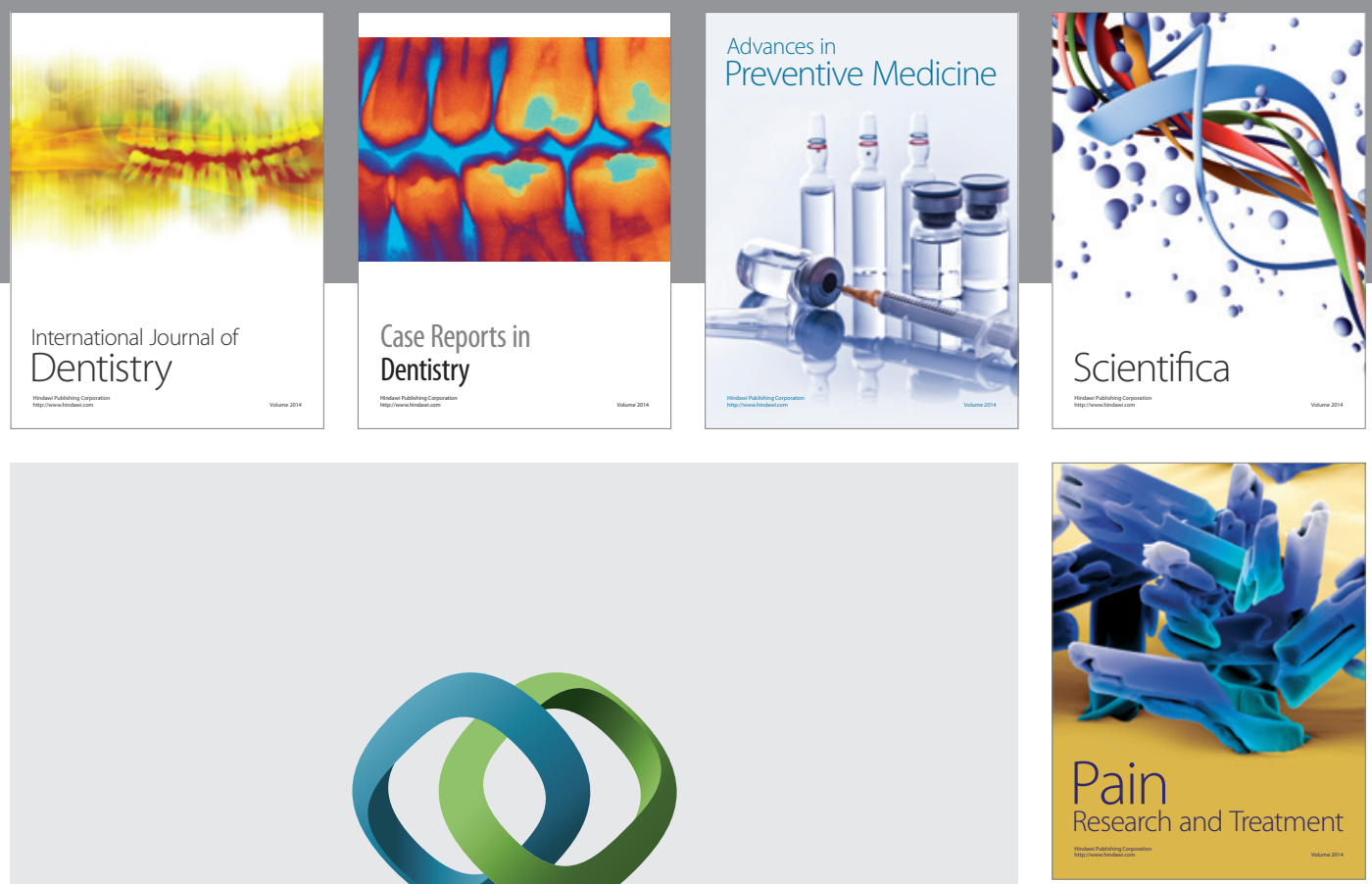

\section{Hindawi}

Submit your manuscripts at

http://www.hindawi.com
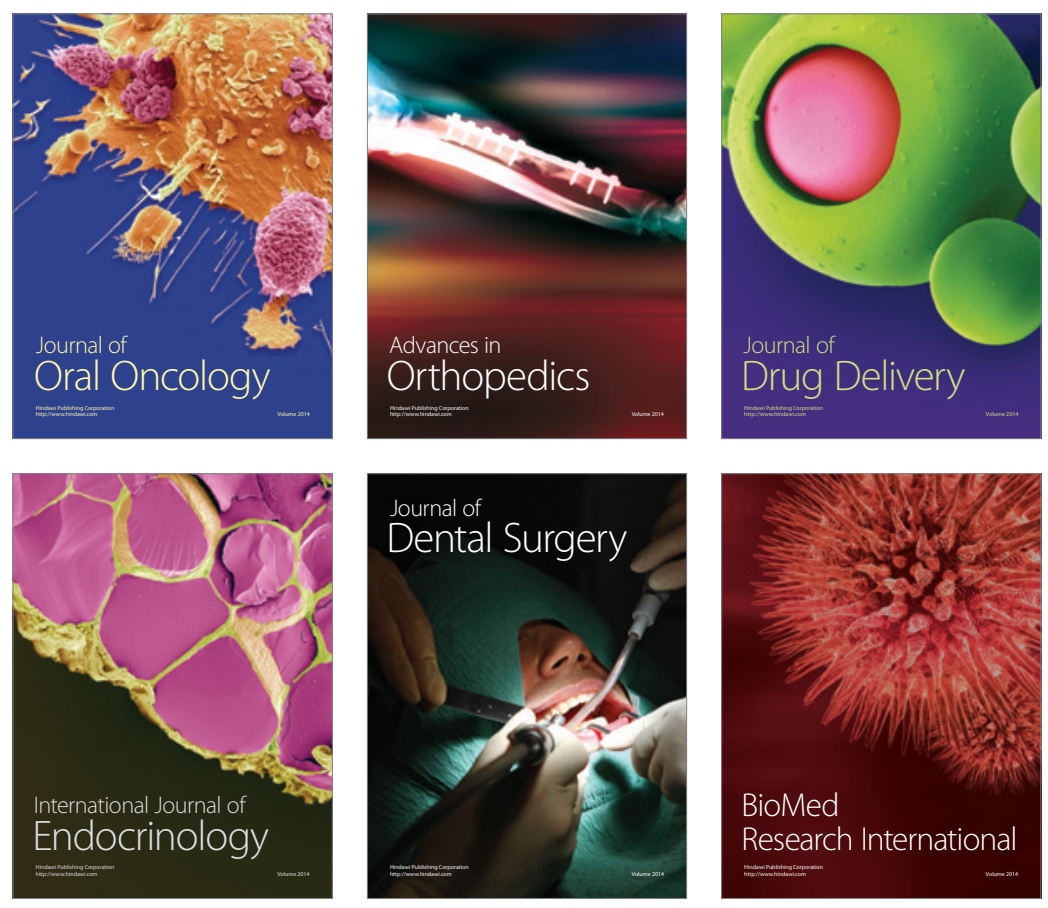

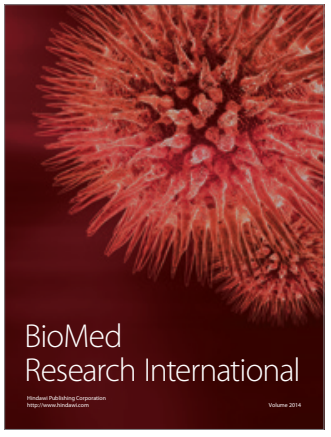

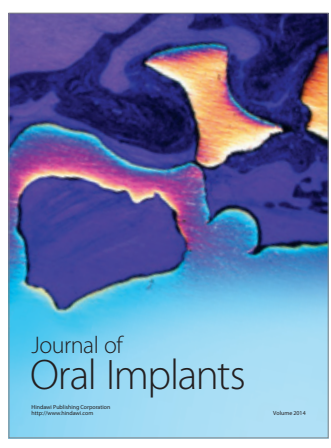
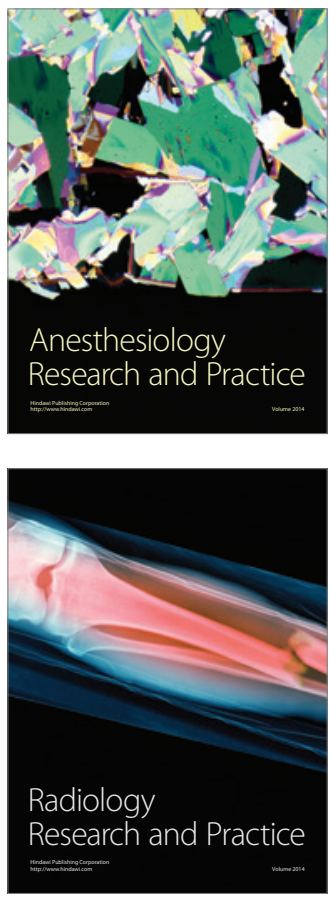